\title{
Superhydrophobic Coating Polymer/Silica Nanocomposites: Enhancing Water Vapor Barrier Properties of Packaging Paper with Ultra-Thin PS/silica Nanocomposite Polymer Coating
}

\author{
Saber A. Ibrahim and Maha Z. Sultan* \\ Packaging Materials Department, National Research Centre, El behoth Street 33, \\ 12622, Dokki, Cairo, Egypt.
}

$\mathbf{R}$ EGARDLESS, the advantages of packaging paper and paperboards they lose their marketing share to the plastics because of their inadequate barrier properties due to their porous structure. They have no resistance against gases, moisture, and vapors. For that reason, the aim of this study is imparting roughening to cellulose fiber surface by applying ultra-thin coating of PS / silica nanocomposite. The effect of hydrophobic coating on surface morphology (SEM), contact angle, water vapor permeability (WVP), water sorption isotherm, and mechanical properties were investigated. The maximum contact angle $>120^{\circ}$ was obtained at $\mathrm{SiO}_{2}$ nanoparticle concentration (4\%). WVP results revealed remarkable sharp decline in WVP of coated paper compared with uncoated one with increasing coating thickness beyond ( $4 \%) \mathrm{SiO}_{2}$ nanoparticle content attained WVP $\left(0.0003 \mathrm{~g} \mathrm{~Pa}^{-1} \mathrm{~s}^{-1} \mathrm{~m}^{-1}\right)$ compared with uncoated sample $\left(0.0126 \mathrm{~g} \mathrm{~Pa}^{-1} \mathrm{~s}^{-1} \mathrm{~m}^{-1}\right)$. The sorption isotherm of PS/ silica nanocomposite coated paper results have been fitted using BET model. The curves exhibited the characteristic sigmoid-shaped type II isotherm. The monolayer water content values $\left(\mathrm{M}_{0}\right)$ range between $0.00005-0.00280 \mathrm{~g}$ water $/ \mathrm{g}$ dry film. The applied PS/silica nanocomposite on mechanical properties showed enhancement in each of burst, short span, tensile strength. However, roughness and elongation decreased further than $(4 \%) \mathrm{SiO}_{2}$ nanoparticle content.

Keywords: Coating, Packaging, Contact angle, Barrier properties, Water vapor permeability, Polymer composite, Water sorption isotherm.

\section{Introduction}

Modern packaging materials have received great attention to global trends and consumer preferences. The fiber-based including paper and paperboards are the most common used packaging materials. They have many advantages than the plastic candidates like recyclability, biodegradability, and renewability. However, the most undesirable characters of fiber - based packaging are the poor barrier properties especially water vapor, gas, and grease properties. However, there are still attempts to enhance barrier properties by attaining high grafting efficiency to fibers. The most commonly technique used to enhance water vapor permeability is the lamination with petrochemical-based polymeric materials such as polyethylene, ethylene vinyl alcohol, and polyvinyl chloride derivatives or aluminum film [1]. Over the past few years, the application of nanotechnology can attend to all these principal requirements of packaging functions. Up to now, polymer nanotechnology can provide new packaging materials of antimicrobial, mechanical, and good barrier properties, with nano sensors for monitoring the conditions of food during storage and transport of products [2]. Numerous applications of nanomaterial in packaging and safety include polymer/clay nanocomposites as high barrier packaging materials [3]. The most acceptable nanoscale fillers are layered silicate nanoclays such as kaolinite and montmorillonite. In food packaging, the development of high barrier properties against the diffusion of water vapor, oxygen, carbon dioxide, and flavor compounds is important issue [4]. These applications were chosen because they do not involve direct addition of nanoparticles to consumed foods, and thus are more likely to be marketed to the public in the short term.

*Corresponding author e-mail: mahasultan21@yahoo.com

DOI: 10.21608/EJCHEM.2018.3842.1374

C2017 National Information and Documentation Center (NIDOC) 
Recently, a number of trends is including chemical modifications of cellulose fibers or hand sheets have been done to enhance the barrier properties including imparting the fibers hydrophobicity $[5,6]$.

Nowadays, researchers tend to prepare packaging paper of good barrier properties by fabricating superhydrophobic surfaces. This was done by creating both of High-energy surface compositions and certain roughness [7]. Therefore, many treatments have been designed and applied to impart superhydrophobic paper as coating on paper surface like fluorizated $\mathrm{SiO}_{2}$ nanoparticles [8] and long chain fluoro containing $\mathrm{SiO}_{2}$ nanoparticles $[9,10]$. However, some researchers have attempted to render paper substrate hydrophobic through building micro/ nanostructures to avoid using pentafluoroethane precursors [11, 12]. They created plasma deposition of diamond-like carbon onto paper surface from acetylene precursor instead of pentafluoroethane [13].

The applied research techniques based on simple synthesis strategy to form superhydrphobic coating through miniemuslion encapsulation of $\mathrm{SiO}_{2}$ nanoparticles. The scientific target of this study is to apply PS/ silica nanocomposite polymer coating to the Kraft packaging paper creating ultra-thin coating to paper imparting high water vapor barrier property, which is sufficient to meet the requirements for high barrier applications. Therefore surface morphology of coated paper was evidenced using SEM technique; physical properties including contact angle measurements, water vapor permeability, water sorption isotherm, and water absorption were investigated. Therefore the effects of coating on the mechanical properties were studied.

\section{Experimental}

\section{Materials}

Styrene (Aldrich, Germany) was purified before use. Tetraethoxysilane (Merck, Germany), sodium lauryl sulfate (SLS) (ACROS, Belgium), 2,2'-Azobis (2-methyl-propionitrile, AIBN) (Aldrich, Germany), Hexadecane (Aldrich, Germany), ammonium chloride, methanol and ethanol are analytical grades. Kraft paper sheets used as substrate to PS/silica nanocomposite polymer coating have grammage of $120 \mathrm{~g} / \mathrm{m}^{2}$ with average thickness of $(0.20143 \pm 0.005)$.

\section{Preparation of $\mathrm{SiO}_{2}$ nanoparticles}

The $\mathrm{SiO}_{2}$ nanoparticles were prepared by the hydrolysis reaction of sodium silicate (17.4 g) and it was dissolved in $300 \mathrm{ml}$ of deionized water, followed by addition of $100 \mathrm{ml}$ of $0.24 \mathrm{M} \mathrm{NH}_{4} \mathrm{Cl}$ solution. The mixture solution was sonicated for 30 minutes with $90 \%$ amplitude. After that, the white product was filtered, washed with deionized water and alcohol until $\mathrm{Cl}^{-}$could not be detected. The resulting product was filtered and dried in vacuum at room temperature for $24 \mathrm{~h}$ to get the $\mathrm{SiO}_{2}$ powder. Polystyrene encapsulated silicone dioxide nanoparticles were prepared through miniemuslion polymerization technique.

\section{Synthesis of polymer nanocomposites}

In protected multi-necks flask, 0.2 mole of styrene monomer and 0.031 mole (hexadecane, HD) as hydrophobe agent were mixed and added to a solution of 0.025 mole sodium lauryl sulfate (SLS) in $73.43 \mathrm{~g}$ of water. The mixture was degassed ( $\mathrm{vac} / \mathrm{N}_{2}$, followed by stirring $30 \mathrm{~min}$ under $\mathrm{N}_{2}$ at $100 \mathrm{~min}^{-1}$ ). The mixture was stirred for $45 \mathrm{~min} . / 800 \mathrm{rpm}$. After that, miniemulsion was prepared by ultrasonication for 10 minutes (90\% Amplitude) with an ultrasonic disintegrator Branson 450W. A slight stream of nitrogen was applied, and the emulsion was cooled with ice water.

Different amounts of $\mathrm{SiO}_{2}$ were dispersed in $22 \mathrm{ml}$ water using sonicator for 5 minutes at $25 \%$ amplitude were added to reaction mixture. The formed mini-emulsion was transferred to the reaction vessel. After short degassing, the temperature was raised to $72{ }^{\circ} \mathrm{C}$. Then, an aqueous solution of initiator (1.8 mmole) AIBN in $7.2 \mathrm{~g}$ water, degassed under $\mathrm{N}_{2}$ for 30 minutes) was added. The reaction was performed at $800 \mathrm{rpm}$ for 4 hours, and then the mixture was cooled to $25^{\circ} \mathrm{C}$.

The reaction vessel was immersed in ice bath to decrease the temperature until room temperature. The dispersion was precipitated in $200 \mathrm{~mL} \mathrm{MeOH}(1 \mathrm{wt} \% \mathrm{HQ})$ and the precipitation was done by dropping the latex solution drop wise addition. Polystyrene was filtrated and dried in vacuum oven overnight.

\section{Paper coating application}

Kraft paper sheets $(28 \times 42 \mathrm{~cm})$ were coated using the film hand multicoated with a bar coating speed of $10 \mathrm{~m} / \mathrm{min}, 10 \mathrm{ml}$ of coating solution was poured on one side of the paper along the width at one end and the applicator rod was immediately swept the coating solution along the length of the papers. All papers were single-side coated either for the front or for the back side. The coated 
papers were dried at room temperature for 24 hours. All the coated papers were cut for property testing and conditioned in a constant-temperature humidity chamber. Conditioning was set at $27^{\circ} \mathrm{C}$ with $65 \% \mathrm{RH}$ for at least $24 \mathrm{~h}$ in accordance with ISO 187.

\section{Characterization of coated papers}

Scanning Electron Microscope (SEM)

The Scanning electron microscope using SEM Model Quanta 250 FEG (Field Emission Gun) attached with EDX Unit (Energy Dispersive X-ray Analyses), with accelerating voltage $30 \mathrm{~K}$.V., magnification $14 x$ up to 1000000 and resolution for Gun.1n).

Physical properties of PS/silica nanocomposite coated packaging Kraft paper

Paper thickness: Paper thickness was measured using a thickness gauge tester (Kalfer $\mathrm{GmbH}$, Germany) accurately $0.01 \mathrm{~mm}$ reading and maximum $10 \mathrm{~mm}$ reading in accordance with ISO 534-2005. Five replicates were done on each sample.

Contact angle measurements: Contact angle measurements were performed using Theata Optical Tensiometer (Dataphysics, Model OAC 13EC, Dataphysics Instrument GmbH, Germany). OAC 13 EC automatic single liquid dispenser was used to automatically dispense a precise volume of liquid drop $(1 \mu \mathrm{l})$ and then descended until the drop contacted with paper surface. It was raised up again such that the water drop stayed at sample surface. The water drop image taken by the camera and then was analyzed by Data physics software using Young fitting mode to obtain the contact angles.

Water vapor permeability: WVP tests were carried out by ASTM method E96 (1996) with some modification (Yu J.G. et al., 2008). The films were cut into circles sealed with melted paraffin and stored in desiccator at $25{ }^{\circ} \mathrm{C}$ with relative humidity zero maintained using anhydrous calcium sulfate in the cups of $2 \mathrm{~cm}$ diameter. Each cup was placed in a desiccator containing saturated sodium chloride solution to provide a constant relative humidity of $75 \%$. Water vapor transport was determined by the weight gain of the permeation cup. Changes in the weight of the cups were recorded as a function of time. Slope was calculated by linear regression (weight changes vs. time) and the correlation coefficients for all reported data were $\geq 0.99$. The water vapor transmission rate (WVTR) was defined as the slope $(\mathrm{g} / \mathrm{s})$ divided by the transfer area $\left(\mathrm{m}^{2}\right)$. After the permeation tests, films thickness was measured and WVP $\left(\mathrm{g} \mathrm{Pa}^{-1} \mathrm{~s}^{-1} \mathrm{~m}^{-1}\right)$ was calculated as:

$\mathrm{WVP}=\mathrm{WVTR} / P\left(R_{1}-R_{2}\right) \cdot \mathrm{X}$

Where $P$ is the saturation vapor pressure of water (Pa) at the test temperature $\left(25^{\circ} \mathrm{C}\right), R_{l}$ is the $\mathrm{RH}$ in the desiccator, $R_{2}$ is the $\mathrm{RH}$ in the permeation cups, and $\mathrm{X}$ is the film thickness $(\mathrm{m})$. Under these conditions, the driving force $P\left(R_{1}-R_{2}\right)=$ $1753.55 \mathrm{~Pa}$.

Determination of water sorption isotherm: The equilibrium moisture sorption isotherm of the samples at $30^{\circ} \mathrm{C}$ was evaluated. Equilibrium moisture content at $30^{\circ} \mathrm{C}(\mathrm{g}$ absorbed water/g dry film) was measured for each water activity. Experimental data were modeled using the BET [14]: BET model:

$\left.\mathrm{M}=\left[\left(\mathrm{M}_{\mathrm{o}}+\mathrm{T}\right) \mathrm{Ca}_{\mathrm{w}}\right] /\left[\left(1-\mathrm{a}_{\mathrm{w}}\right)\left(1-\mathrm{a}_{\mathrm{w}}\right)+\mathrm{Ca}_{\mathrm{w}}\right)\right]$

Where, $\mathrm{M}_{\mathrm{o}}$ and $\mathrm{C}$ are constants which are obtained from the slope and intercept of the linear plots of $\mathrm{a}_{\mathrm{w}} /\left[\left(1-\mathrm{a}_{\mathrm{w}}\right) \mathrm{M}\right.$ vs. $\mathrm{a}_{\mathrm{w}}$

Saturated salt solutions of potassium hydroxide, potassium carbonate, sodium dichromate, sodium nitrite, sodium chloride, chloride were used as aw standards of $0.0738,0.43,0.54,0.64,0.75$, 0.83 respectively. The above-saturated solutions were placed in different desiccators to obtain different relative humidities (RH) for the exposure of PS/silica nanocompositecoated Kraft paper, and then conditioned to $65 \% \mathrm{RH}$ at $30 \pm 1^{\circ} \mathrm{C}$ before they were exposed to different relative humidities. The initial moisture content (IMC) of PS/silica nanocompositecoated Kraft paper (in duplicate) were measured on dry weight basis by drying in vacuum oven at $60 \pm 2{ }^{\circ} \mathrm{C}$ at $550 \mathrm{~mm}$ $\mathrm{Hg}$ pressure till a constant weight was obtained. The approximate time allowed for drying the specimens was $6-8 \mathrm{~h}$. The sorption isotherm determination was performed by exposing $1 \mathrm{~g}$ (approximately) of the film specimen in desiccators having different aw from 0.0738 to 0.83 at $30 \pm 1{ }^{\circ} \mathrm{C}$. The samples were weighed until equilibrium (i.e., $+0.05 \%$ change in moisture content) was attained for a period of 1-7 days [15].

Water absorption: PS/silica nanocompositecoated Kraft papers were measured for water absorption. These properties were measured by Cobb's test using COBB Tester Model No.61-05 accordance with Fefco Testing Egypt.J.Chem. 62, No. 1 (2019) 
Method No.7. The Cobb test method is usually conducted for water absorption measurement. The samples were cut into rectangle of size $14 \times 14 \mathrm{~cm}$ and test performed within one minute. The water absorption percentage was determined as:

$\mathrm{A}=\left(\mathrm{W}_{2}-\mathrm{W}_{1}\right) / \mathrm{W}_{1}$ X 100

Where $\mathrm{W}_{1}$ and $\mathrm{W}_{2}$ are the weights of the PS/ silica nanocomposite coated Kraft paper sheets before and after water absorption respectively.

\section{Mechanical properties}

Mechanical properties include tensile strength (TS), elongation at break (EAB) were determined by standard method (ASTM D-882-91, 1996) using a Universal Testing Machine (model LLOYD). The films were conditioned at $25^{\circ} \mathrm{C}$ and relative humidity $75 \%$ for 24 hours. To determine the mechanical properties, the samples were cut into rectangle of size $20 \times 70 \mathrm{~mm}$ and fixed on the grip of the device with span distance $50 \mathrm{~mm}$. the average thickness of film was $52 \mu \mathrm{m}$. TS was determined by dividing the maximum force $(\mathrm{F})$ at break by cross - sectional area (S) of film as equation (1), and expressed in MPa. The EAB was calculated based on the length extended $(\Delta \mathrm{L})$ and the initial length $\left(\mathrm{L}_{\mathrm{o}}\right)$ of the film and expressed in $\%$ as equation (2) [16].

$$
\begin{aligned}
& \mathrm{TS}=\mathrm{F} / \mathrm{S} \\
& \mathrm{EAB}=\Delta \mathrm{L} / \mathrm{L}_{\mathrm{o}} \times 100
\end{aligned}
$$

Roughness and burst properties were measured according to Fefco Testing Method No.2 and No.4 respectively using Roughness Tester Bendtsen and Automatic Burst Tester MESSMER BÜCHEL.

Short span compression (SCT) test performed on coated paper strips according to standard test (ISO 9895-TAPPI T826 using Short Span Compression Tester "SCT" SCM-1 model Load cell range $0-500 \mathrm{~N}$, free span $0.7 \pm 0.05 \mathrm{~mm}$, and testing speed $3 \pm 0.5 \mathrm{~mm} / \mathrm{min}$. This test is used to determine compression strength of liner papers with grammage range of $100-400 \mathrm{~g} / \mathrm{m}^{2}$ in $\mathrm{kN} / \mathrm{m}^{2}$ units. The sample was in the form of rectangle with a minimum length of $120 \mathrm{~mm}$ and fixed width of $15 \mathrm{~mm}$ between clamps.

\section{Results and Discussion}

Scanning electron microscope (SEM)

SEM of uncoated and PS/silica nanocomposite polymer coated Kraft paper were captured together in Fig. 1. SEM image of uncoated paper showed the typical porous and fibrous structure of any fiber-based materials. The pores and the interspaces of paper fibers are also so clear. PS/ silica nanocomposite coating applied on paper surface image showed blocking the interspace and pores of paper surface. The coating of PS/silica nanocomposite showed smooth and homogeneous coating with uniform of $\mathrm{SiO}_{2}$ nanoparticles distribution on the paper surface which causes roughness and hydrophobicity to paper.

Effect of PS/silica nanocomposite polymer coating on physical properties

Contact angle measurements

Since PS/silica nanocomposite coating applied on paper surface was adequate enough to block the interspace of paper fibers as shown in SEM images in Fig. 1. To further testify this, contact angles of water droplet on PS/silica nanocomposite polymer coated paper were characterized by static water contact angle (CA) measurements as shown in Fig. 2. The roughness created by the PS could explain the increase on water CA and hydrophobic properties of all PS/silica nanocomposite polymer coated Kraft paper compared with control. The results can suggest that an increase in $\mathrm{SiO}_{2}$ nanoparticles concentration can generate even better values of water CA to certain limit. With the increase of $\mathrm{SiO}_{2}$ nanoparticles concentration, roughness is enhanced which leads to maximum water contact angle $>120^{\circ}$ at $\mathrm{SiO}_{2}$ nanoparticles concentration $(4 \%)$. Then, there is a minor drawback for contact angle values with further increasing of $\mathrm{SiO}_{2}$ nanoparticles concentration. These results revealed that $\mathrm{SiO}_{2}$ nanocoatings to surface benefits the wetting of the surface, and therefore the water contact angles decrease with increasing $\mathrm{SiO}_{2}$ nanoparticles concentration.

The effect of coating layer thickness on water vapor permeability and water absorption

The average thickness values of PS/silica nanocomposite polymer coated Kraft packaging paper are presented in Table 1, it is clear that, $\mathrm{SiO}_{2}$ nanoparticles content has dramatic effect on thickness of coating layer. There is a slight increase in thickness of coated paper with increasing $\mathrm{SiO}_{2}$ nanoparticles contents with minor standard deviation and standard errors. Water vapor permeability is the mass of water vapor in gram pass through a unit area in a unit time under specific conditions of humidity and temperature.

The effectiveness of packaging materials is generally associated to their mass-transport 


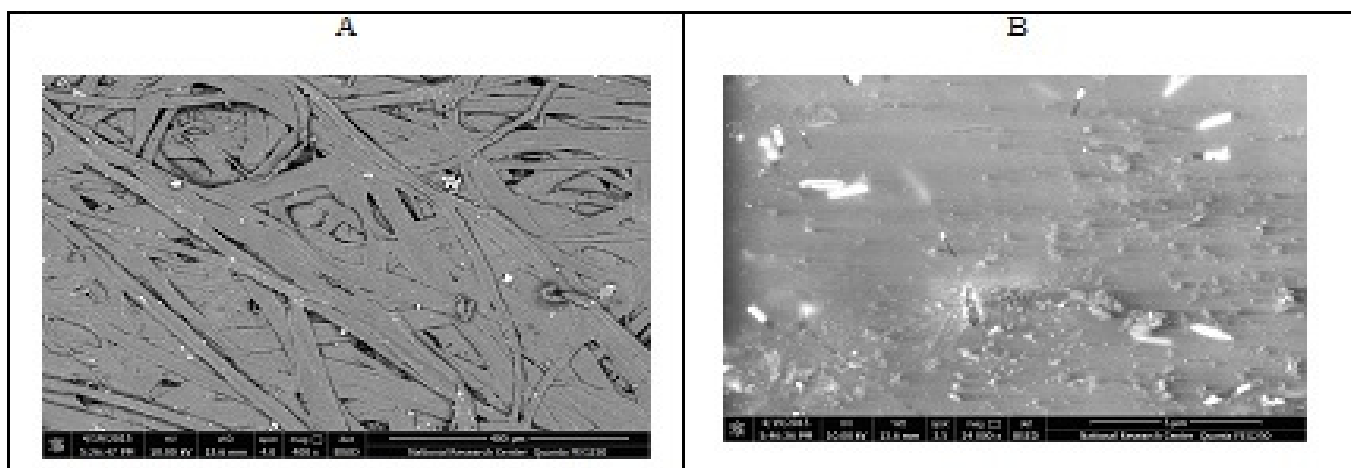

Fig. 1. SEM images of uncoated (A) and P S/Silica nanocomposite coated Kraft packaging paper (B).

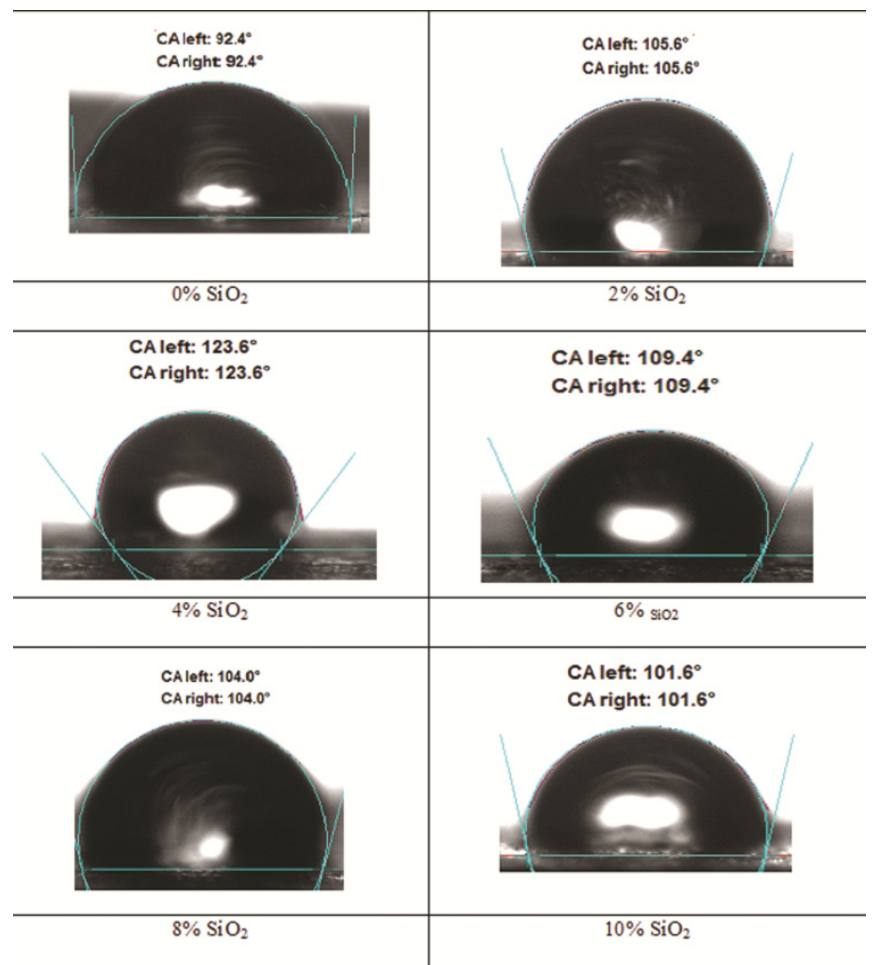

Fig. 2. Contact angle measurements of PS and PS/silica nanocomposite coated Kraft paper.

TABLE 1. Shows the effect of PS/ silica nanocomposite coating layer thickness on the physical properties of coated Kraft paper.

\begin{tabular}{ccccccc}
\hline $\begin{array}{c}\mathbf{S i O}_{2} \\
\text { nanoparticle } \\
\text { content }\end{array}$ & $\begin{array}{c}\text { Mean value of } \\
\text { PS/silica } \\
\text { nanocompositecoated } \\
\text { Kraft paper } \\
\text { thickness (mm) }\end{array}$ & $\begin{array}{c}\text { Thickness } \\
\text { of PS/silica } \\
\text { nanocomposite } \\
\text { coating layer } \\
(\mathbf{m m})\end{array}$ & $\begin{array}{c}\text { Standard } \\
\text { deviation } \\
\mathbf{( S d} \pm)\end{array}$ & $\begin{array}{c}\text { Standard } \\
\text { error } \\
(\mathbf{E r} \pm)\end{array}$ & $\begin{array}{c}\text { Water vapor } \\
\text { permeability } \\
\left(\mathbf{g ~ P a}^{-1} \mathbf{s}^{-1} \mathbf{m}^{-1}\right)\end{array}$ & $\begin{array}{c}\text { Water } \\
\text { absorption } \\
\mathbf{\%}\end{array}$ \\
\hline $0 \% \mathrm{SiO}_{2}$ & 0.2014 & 0.0000 & 0.0140 & 0.0050 & 0.0126 & 80.070 \\
$2 \% \mathrm{SiO}_{2}$ & 0.2414 & 0.0400 & 0.0100 & 0.0040 & 0.0051 & 25.930 \\
$4 \% \mathrm{SiO}_{2}$ & 0.2642 & 0.0657 & 0.0330 & 0.0120 & 0.0003 & 16.230 \\
$6 \% \mathrm{SiO}_{2}$ & 0.2671 & 0.0671 & 0.0138 & 0.0052 & 0.0029 & 18.620 \\
$8 \% \mathrm{SiO}_{2}$ & 0.2757 & 0.0742 & 0.0190 & 0.0070 & 0.0028 & 21.780 \\
$10 \% \mathrm{SiO}_{2}$ & 0.2857 & 0.0842 & 0.0078 & 0.0029 & 0.0070 & 23.090 \\
\hline
\end{tabular}


properties. The capability to avoid or to limit moisture transfer between the food and the surrounding atmosphere is critical for food quality and safety concerns. The key factors affecting transport properties of coated packaging materials are the type of coating material, coating weight, coating composition [17].

The effect of PS/silica nanocomposite polymer coating thickness on water vapor permeability (WVP) of PS/ silica nanocomposite polymer coated Kraft packaging paper is displayed in Table 1. Coating layer thickness is very important parameter in determining physical properties of coated packaging papers. As clear, there was remarkable sharp decline in WVP of coated paper compared with uncoated one with increasing coating thickness afar $4 \%$ nanosilica content give WVP $\left(0.0003 \mathrm{~g} \mathrm{~Pa}^{-1} \mathrm{~s}^{-1}\right.$ $\mathrm{m}^{-1}$ ) and then, the increased trend continued again. This can be assigned to the fact that coating layer was deposited on the surface and penetrated into cellulose matrix clogging abundant interspaces and cavities which could trap more water vapor. Thus, the coated paper presented a water-repellency characteristic when the water vapors pass.

The effect of PS/ silica nanocomposite polymer coating layer thickness on water absorption of coated Kraft packaging paper is presented in Table 1. There is a sharp drop in water absorption among uncoated and coated samples. The water absorption decreases with increasing coating thickness layer and consequently $\mathrm{SiO}_{2}$ nanoparticles content increase. The lowest water absorption percent was $(16.23 \%)$ at $(0.264 \mathrm{~mm})$ coating thickness layer with $\mathrm{SiO}_{2}$ nanoparticles content (4\%) based on PS content. This could be referred to that the ultra-thin coating of hydrophobic PS/ silica nanocomposite coating layer acts as a barrier to water absorption, this coating layer penetrate into cellulose matrix interspaces moreover deposition onto surface creating rough surface and grooves preventing water absorption. General conclusion, PS/silica nanocomposite polymer coating applied onto packaging paper polymer has already proven to provide good barrier properties in respect to the permeation of water vapor.

\section{Moisture sorption isotherm}

The moisture sorption isotherm of PS/ silica nanocomposite coated papers shows that \%EMC increased with increasing relative moisture as shown in Fig. 3. Generally, the amount of water absorbed increased with increasing water activity. The sorption isotherm of control (without hydrophobic coating) has the representative sigmoid-shaped type II isotherm. This behavior is due to the high hydrophilic sites into cellulose network [18]. The PS/ silica nanocomposite polymer coated paper at $\mathrm{SiO}_{2}$ nanoparticles concentration (4\%) showed the lowest \%EMC. However, with increasing silica nanoparticles contents, \%EMC increased. This behavior may be associated with the agglomeration of silica nanoparticles. The sorption model, BET was used to predict which model is the best explained the sorption mode of PS/ silica nanocomposite coated paper. The experimental sorption isotherm data were tested to fit the model equation. The corresponding coefficient $\mathrm{R}^{2}$ and the constants obtained from this model are listed in Table 2. The monolayer water content values $\left(\mathrm{M}_{0}\right)$ of the PS/ silica nanocomposite coated papers of different silica nanoparticles contents for the BET model range between 0.00005- 0.00280 $\mathrm{g}$ water/g dry film. The $\mathrm{M}_{0}$ value indicates the maximum moisture content which was adsorbed in a mono-layer of $1 \mathrm{~g}$ of dry film. This is determined by the number of sorption sites [19, 20]. Therefore, $M_{0}$ is recognized as the moisture content provide the longest time period with minimum quality loss at a given temperature. Below it, the minimum rate of deterioration was accomplished. Hence at a given temperature, the safest water activity level is that corresponding to $\mathrm{M}_{0}$ or lower. The monolayer water content decreased with increasing content of silica nanoparticles until giving the maximum lowest value at silica nanoparticles concentration (4\%), then it begins to increases again with increasing silica nanoparticles content. This behavior may be attributed to aggregation of increased silica nanoparticles content.

The high value of this energy constant $\left(\mathrm{C}_{\mathrm{BET}}\right)$ demonstrates that water molecules more strongly adsorbed in the active sites of the matrix [21]. A reduction in the $\mathrm{C}_{\mathrm{BET}}$ means a decrease in the value of energy of heat sorption for monolayer. The results of $\left(\mathrm{C}_{\mathrm{BET}}\right)$ reveal that silica nanoparticles (4\%) showed the lowest value $(0.132)$. It is proposed that the fewer active sites were available to bind water molecules. Those results are in agreement with the results of contact angle as shown before. 


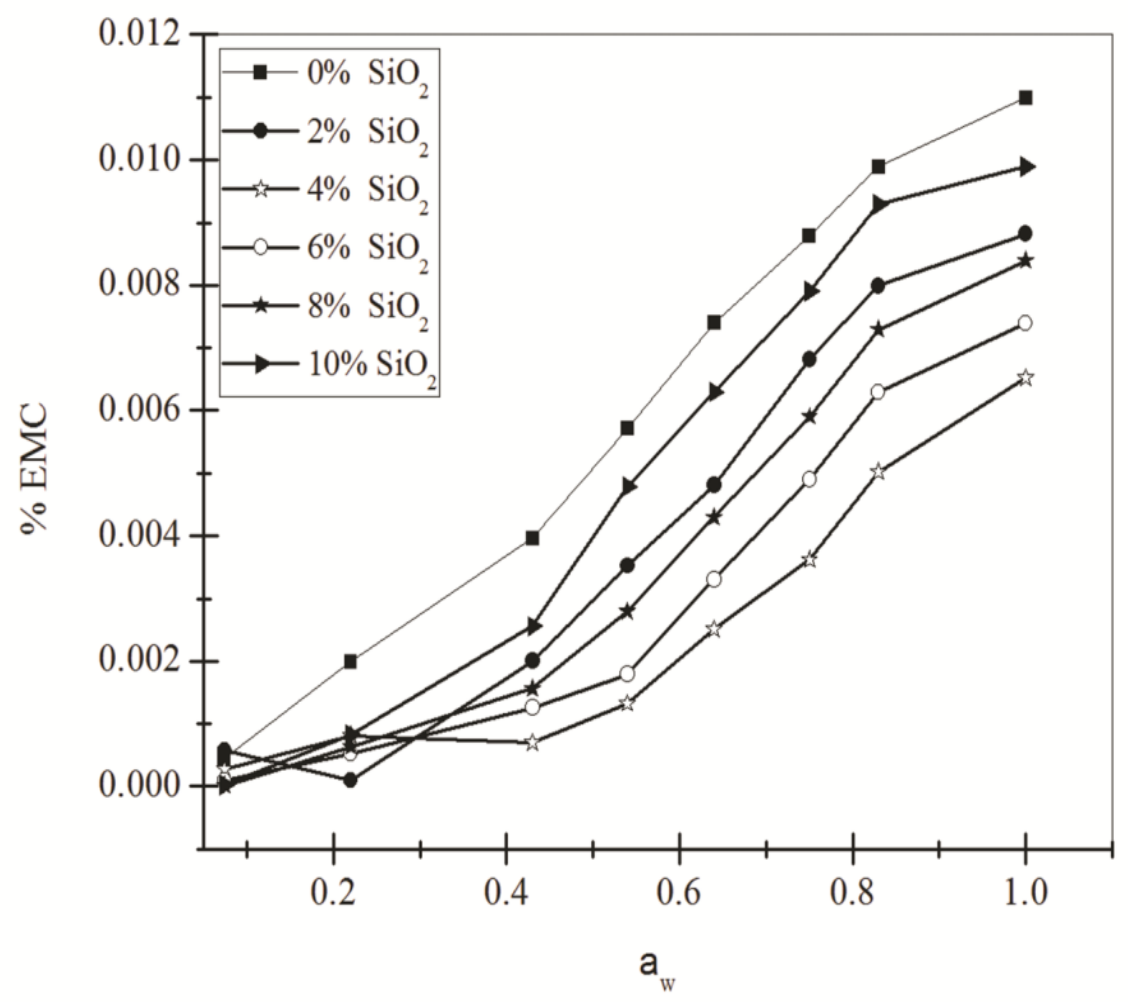

Fig. 3. Equilibrium moisture content percentage of PS/silica nanocomposite coated Kraft paper at different relative humidities.

TABLE 2. Water sorption isotherms model constants of PS/silica nanocompositecoated Kraft paper with different relative humidities at $30^{\circ} \mathrm{C}$.

\begin{tabular}{cccc}
\hline $\mathbf{S i O}_{2}$ nanoparticle contents & $\mathbf{R}^{2}$ & $\mathbf{M}_{\mathbf{o}}(\mathbf{g} / \mathbf{g})$ & $\mathbf{C}$ \\
\hline $0 \% \mathrm{SiO}_{2}$ & 0.920 & 0.00189 & 17.901 \\
$2 \% \mathrm{SiO}_{2}$ & 0.992 & 0.01682 & 29.271 \\
$4 \% \mathrm{SiO}_{2}$ & 0.980 & 0.00144 & 52.910 \\
$6 \% \mathrm{SiO}_{2}$ & 0.973 & 0.00116 & 491.90 \\
$8 \% \mathrm{SiO}_{2}$ & 0.971 & 0.00118 & 77.809 \\
$10 \% \mathrm{SiO}_{2}$ & 9.995 & 0.09633 & 26.940 \\
\hline
\end{tabular}

The effect of PS/silica nanoparticles polymer coating on mechanical properties of Kraft paper

The mechanical and strength properties of paper reflect changes to paper as a result of any chemical treatment. The result data was used to investigate the effect of coating Kraft packaging paper with PS/silica nanocomposite polymer on mechanical properties were displayed in Table 3. It was found that roughness increased dramatically with increasing $\mathrm{SiO}_{2}$ nanoparticles content accompanied by increasing in each of elongation and then they showed small decrease beyond $\mathrm{SiO}_{2}$ nanoparticles (4\%) content. However, the increasing $\mathrm{SiO}_{2}$ nanoparticles content led to an increase each of burst, short span, and tensile strength. These results may be owed to agglomeration of increased $\mathrm{SiO}_{2}$ nanoparticles content in certain points across the paper surface. 
TABLE 3. shows the effect of PS/ silica nanocomposites coating on mechanical properties of coated Kraft paper.

\begin{tabular}{|c|c|c|c|c|c|}
\hline $\begin{array}{c}\mathrm{SiO}_{2} \text { nanoparticle } \\
\text { contents }\end{array}$ & $\begin{array}{c}\text { Roughness } \\
(\mathrm{ml} / \mathrm{min})\end{array}$ & $\begin{array}{l}\text { Burst } \\
\text { (KPa) }\end{array}$ & $\begin{array}{c}\text { Short span } \\
\left(\mathbf{N} / \mathbf{m}^{2}\right)\end{array}$ & $\begin{array}{c}\text { Tensile } \\
\text { strength }\left(\mathbf{N} / \mathbf{m}^{2}\right)\end{array}$ & $\begin{array}{c}\text { Elongation, } \\
\%\end{array}$ \\
\hline $0 \% \quad \mathrm{SiO}_{2}$ & 0.000 & 712 & 1.84 & 0.0748 & 3.30 \\
\hline $2 \% \quad \mathrm{SiO}_{2}^{2}$ & 313.0 & 872 & 2.18 & 0.0812 & 4.42 \\
\hline $4 \% \quad \mathrm{SiO}_{2}$ & 1611 & 872 & 2.28 & 0.0816 & 7.31 \\
\hline $6 \% \mathrm{SiO}_{2}^{2}$ & 1282 & 904 & 2.59 & 0.0820 & 7.11 \\
\hline $8 \% \quad \mathrm{SiO}_{2}^{2}$ & 827.0 & 920 & 3.26 & 0.0841 & 6.19 \\
\hline $10 \% \mathrm{SiO}_{2}$ & 346.0 & 920 & 3.38 & 0.0831 & 5.96 \\
\hline
\end{tabular}

\section{Conclusion}

PS/silica nanocomposite coating with different $\mathrm{SiO}_{2}$ nanoparticles contents has successfully imparted surface- - roughening to cellulose packaging paper of enhanced physical and water barrier properties. The coating achieved contact angle $>120^{\circ}$, at $\mathrm{SiO}_{2}$ nanoparticles (4\%) and significant reduced WVP. The fitted curves of water sorption isotherm using BET model follow the characteristic sigmoid-shaped type II isotherm. The monolayer water content value $\left(\mathrm{M}_{0}\right)$ was range between (0.00005- 0.00280 $\mathrm{g}$ water/g dry films). The applied PS/silica nanocomposite coating on mechanical properties showed enhancement in each of burst, short span, tensile strength. However, roughness and elongation decreased beyond $\mathrm{SiO}_{2}$ nanoparticles concentration (4\%).

\section{References}

1. Eva-Lena H., Jarmo R., Kristiina P.-L., Taina O-A., Tarja T., Enhancing the barrier properties of paper board by a novel lignin coating. Industrial Crops and Products, 50, 694- 700 (2013).

2. Clara S., Donatella D., Sossio C., .Food packaging based on polymer nanomaterials. Progress in Polymer Science, 36, 1766-1782 (2011).

3. Majeed K., Jawaid M., Hassan A., Abu B. A., Abdul Khalil H.P.S., Salema A.A., Inuwa I., Potential materials for food packaging from nanoclay/natural fibres filled hybrid composites. Materials and Design, 46, 391-410 (2013).

4. Jong-Whan R., Hwan-Man P., Chang-Sik H., Bionanocomposites for food packaging applications. Progress in Polymer Science, 38, 1629-1652 (2013).

5. Pan Y., Xiao H., Song Z., Hydrophobic Egypt.J.Chem. 62, No. 1 (2019) modification of cellulose fibers by cationic modified polyacrylate latex with core-shell structure. Cellulose, 20, 485-494 (2013).

6. Rodionova G., Lenes M., Surface chemical modification of microfibrillated cellulose: Improvement of barrier properties for packaging applications. Cellulose, 18, 127-134 (2011).

7. Wewei Z., Peng L., Liying Q., Huining X., Fabrication of superhydrophobic paper surface via wax mixture coating. Chemical Engineering Journal, 250, 431-436 (2014).

8. Yang H., Deng Y., Preparation and physical properties of superhydrophobic papers. Journal of Colloid Interface Science, 325, 588-593 (2008).

9. Wang H., Fang J., Cheng T., Ding J., Qu L., Dai L., Wang X., Lin T., One step coating of fluorocontaining silica nanoparticles for universal generation of surface superhydrophobicity. Chemical Communication, 7, 877-879 (2008).

10. Wang H., Ding J., Xue Y., Wang X., Lin T., Superhydrophobic fabrics from hybrid silica solgel coating: structural effect of precursors on wettability and washing durability. Journal of Material Research, 25, 1336-1343 (2010).

11. Balu B., Breedveld V., Hess D.W., Fabrication of "roll off" and sticky superhydrophobic cellulose surfaces via plasma processing. Langmuir, 24, 4785-4790 (2008).

12. Balu B., Kim J.S., Breedveld V., Hess D.W., Tunability of the adhesion of water drops on a superhydrophobic paper surface via selective plasma etching. Journal Adhesive Science Technology, 23, 361-380 (2009).

13. Li L., Roethel S., Breedveld V., Hess D.W., Creation of low hysteresis superhydrophobic paper by deposition of hydrophilic diamond-like 
carbon film. Cellulose, 20, 3219-3226 (2013).

14. Jangchud A., Chinnan M.S., Properties of peanut protein film: Sorption isotherm and plasticizer effect, Lebensmittel-Wissenschaft undTechnologie, 32 (2), 89-94 (1999).

15. Jagadish R.S., Baldev R., Moisture sorption studies of $\mathrm{PEO} /$ starch blended films for food packaging applications. International Journal of Agriculture and Food Science Technology, 4 (9), 923-932 (2013).

16. Elena V., Eleonora W., Slobodanka K., Vitor D. A., Margarida M-M., Impact of chitosanbeeswax edible coatings on the quality of fresh strawberries (Fragariaananassa cv Camarosa) under commercial storage conditions. LWT-Food Science and Technology, 52 (2), 80-92 (2013).

17. Aloui, H., Khwaldia, K., Ben Slama, M., Hamdi, M., Effect of glycerol and coating weight on functional properties of biopolymer-coated paper.
Carbohydrate Polymers, 86, 1063-1072 (2011).

18. Pornchai R., Rungsiri S., Moisture Sorption Isotherms of Soy Protein Isolate/Carboxymethyl Chitosan Blend Films. Journal of Agricultural Science and Technology, A 2, 50-57(2012).

19. Strauss U.P., PorcjaR.J., Chen Y., "Volume effects of starch water interactions", in: Levine H., Slade L., (Eds.), Water Relationships in Foods, Plenum Press, New York, p. 836, 1991.

20. BlahovecJ., Vanniotis, S., GAB generalized equation for sorption phenomena. Food Bioprocess Technology, 1, 82-90 (2008).

21. Enrione J.I., Hill S.E., Mitchell J.R., Sorption behavior of mixtures of glycerol and starch. Journal of Agricultural and Food Chemistry, 55, 2956-2963 (2007).

(Received 26/6/2018; accepted 6/9/2018)

\title{
طلاء النانوكمبوزيت من البوليمر و السيليكا الكاره للماء بصورة فائقة: تحسين خصائص نفاذية

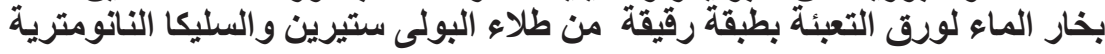 \\ صابر احمد ابراهيم و مهاز زكريا سلطان

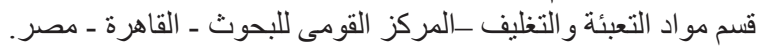

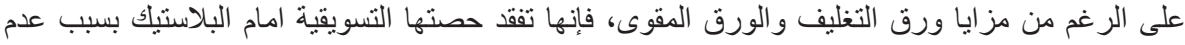

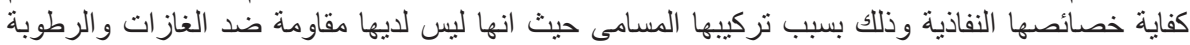

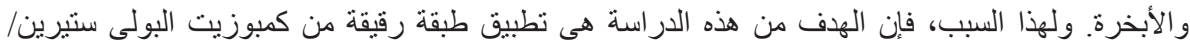

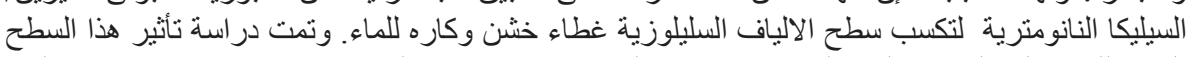

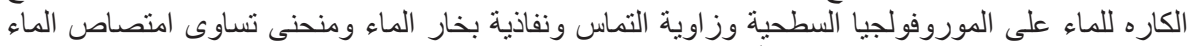

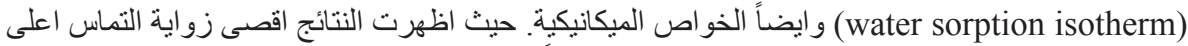

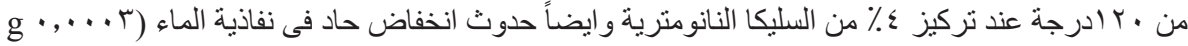

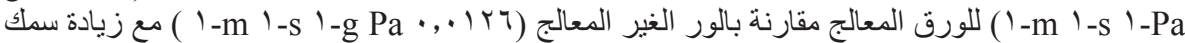

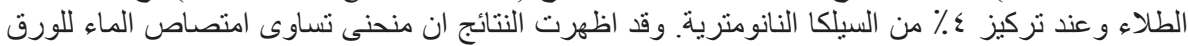

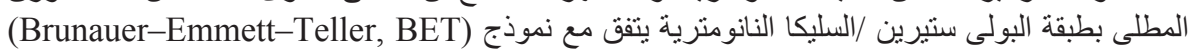

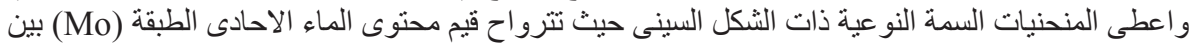

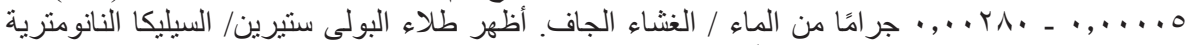

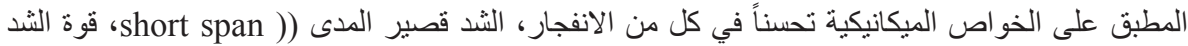

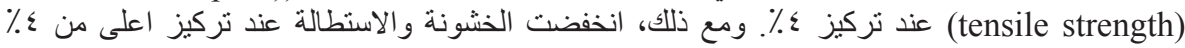
كمتوى للسيلكا النانومترية. 